\title{
Mapping current and future distribution of bat species probable reservoirs of Ebolavirus in Democratic Republic of Congo
}

\author{
Yannick Mugumaarhahama ${ }^{1}$, Marcellin Cokola ${ }^{1}$, Arsène Mushagalusa ${ }^{1}$, Nadège Cirezi ${ }^{1}$, \\ Espoir Bagula ${ }^{1}$, Katcho Karume ${ }^{1}$, and Gustave Mushagalusa ${ }^{1}$ \\ ${ }^{1}$ Université Evangélique en Afrique
}

November 20, 2020

\begin{abstract}
Aim: In recent studies, three species of bat, Hypsignathus monstrosus, Myonycteris torquata and Epomops franqueti were identified as the most likely candidates to be reservoir for Ebolavirus. To help in epidemic preparedness and surveillance, species distribution modeling techniques are useful for predicting where these species are likely to occur in DR Congo. Methods: MaxEnt software was used to model the current and future distribution of the three species in DR Congo based on the occurrence data collected from global biodiversity information facility and environmental covariates collected from Worldclim and USGS. The future distribution were obtained based on two scenario (RCP4.5 and RCP 8.5) of the HadGEM2-CC an IPPC5 climate projections from global climate models $(\mathrm{GCMs})$. Results: The suitable habitat of H. monstrosus, M. torquata and E. franqueti are essentially located from latitude $-5^{\circ}$ to $5^{\circ}$ and longitude $17^{\circ}$ to $30^{\circ}$. Overall, their favourable living areas are located in the territories along the entire northern border and the entire northern part of the eastern border of the DR Congo with varying degrees of importance depending on the territories and species. Three bioclimatic variables have shown to play major role in their spread, the precipitation of the driest quarter, the precipitation of coldest quarter and the temperature annual range. In the future, the suitable area of these species will be decreasing and being essentially located in the Kivu provinces. The change in the ecological niche of these species will differ with respect to future climate scenario. Climate of RCP 8.5 has shown to induce major decrease of their suitable habitat in DR Congo. Main conclusions: The MaxEnt model is potentially useful for forecasting the future adaptive distribution of the three bat species under climate change, and it provides important guidance for comprehensive management of the Ebolavirus risk.
\end{abstract}

Mapping current and future distribution of bat species probable reservoirs of Ebolavirus in Democratic Republic of Congo

Yannick Mugumaarhahama*, Marcellin Cuma Cokola, Arsène Ciza Mushagalusa, Nadège Cizungu Cirezi, Espoir Mukengere Bagula, Katcho Karume and Gustave Nachigera Mushagalusa

Faculty of Agriculture and Environmental Sciences, Université Evangélique en Afrique, PO. Box: 3323 Bukavu, Democratic Republic of Congo

* Corresponding author:

Yannick MUGUMAARHAHAMA

mugumaarhahama@uea.ac.cd

\section{Abstract}

Aim : In recent studies, three species of bat,Hypsignathus monstrosus, Myonycteris torquata and Epomops franqueti were identified as the most likely candidates to be reservoir for Ebolavirus. To help in epidemic 
preparedness and surveillance, species distribution modeling techniques are useful for predicting where these species are likely to occur in DR Congo.

Methods : MaxEnt software was used to model the current and future distribution of the three species in DR Congo based on the occurrence data collected from global biodiversity information facility and environmental covariates collected from Worldclim and USGS. The future distribution were obtained based on two scenario (RCP4.5 and RCP 8.5) of the HadGEM2-CC an IPPC5 climate projections from global climate models (GCMs).

Results : The suitable habitat of H. monstrosus, M. torquata and E. franqueti are essentially located from latitude $-5^{\circ}$ to $5^{\circ}$ and longitude $17^{\circ}$ to $30^{\circ}$. Overall, their favourable living areas are located in the territories along the entire northern border and the entire northern part of the eastern border of the DR Congo with varying degrees of importance depending on the territories and species. Three bioclimatic variables have shown to play major role in their spread, the precipitation of the driest quarter, the precipitation of coldest quarter and the temperature annual range. In the future, the suitable area of these species will be decreasing and being essentially located in the Kivu provinces. The change in the ecological niche of these species will differ with respect to future climate scenario. Climate of RCP 8.5 has shown to induce major decrease of their suitable habitat in DR Congo.

Main conclusions : The MaxEnt model is potentially useful for forecasting the future adaptive distribution of the three bat species under climate change, and it provides important guidance for comprehensive management of the Ebolavirus risk.

Key-words : Species distribution modeling, climate change, Ebolavirus risk, Hypsignathus monstrosus, Myonycteris torquata,

Epomops franqueti

\section{INTRODUCTION}

Humans are affected by a large number of infectious diseases. Most of these infectious diseases are zoonoses. Most of zoonoses have mostly viral origin and are emerging and reemerging. The viral diseases of the Filoviridae family, such Ebola, causes particularly hemorrhagic fevers. Ebola hemorrhagic fever is indeed among the zoonotic viral disease with high mortality rate. The Ebola virus causes severe morbidity and high mortality in humans and wildlife (Bausch and Schwarz, 2014; Fiorilloet al. , 2018).

Number of Ebola virus disease outbreaks have occurred in humans last forty years, with mortality rates reaching values up to 90 \% (Feldmann and Geisbert, 2011; Bausch and Schwarz, 2014). Most of Ebola hemorrhagic fever outbreaks have historically occurred in Central Africa. The first outbreak of Ebola virus in humans was registered in 1976 in Southern Sudan (Report of a WHO/International Study Team, 1978), but likely occurred as early as 1972 in Tandala, DRC. Until 2014, DR Congo had already recorded seven outbreaks of Ebola (Maganga et al. , 2014). There have been two other outbreaks, the latest of which is in Beni-Butembo, which is still at the beginning of 2019. Thus, to date, the DR Congo has already recorded nine Ebola outbreaks being hence one of the countries that have experienced the most Ebola outbreaks.

Up to now, it is not well understood the way the Ebola transmission between outbreaks is maintained (Peterson et al. 2004). However, significant progress has been made in identifying the potential reservoirs of Ebola viruses. Recent studies have identified Hypsignathus monstrosus (H. Allen, 1861), Myonycteris torquata (Dobson, 1878) and Epomops franqueti (Tomes, 1860), three bat species, as the most likely to be the reservoirs of the Ebola viruses (Leroy et al. , 2005; Groseth et al. , 2007; Peterson et al. , 2007; Pourrut et al. , 2009; Haymanet al. , 2010; Olival and Hayman, 2014). Leroy et al. (2007) have shown that in Africa, there is evidence of Ebola outbreaks in humans due to exposure to bats. Based on this evidence, it can be assumed that the distribution of Ebola viruses is limited by certain factors, including the distribution of bats such $H$. monstrosus, M. torquata andE. franqueti (Nyakarahuka et al. , 2017).

It is believed that climate change will affect future distribution of bats reservoirs of Ebola virus. A number of 
studies have reported the impact of climate change on Ebola outbreaks in Africa and the migratory patterns of bats (Newson et al. , 2009). Indeed, migratory species are particularly likely to be affected by climate change at some point in their life cycles, and there is already compelling evidence for impacts on a wide range of birds, marine mammals, fish, sea turtles, squid, bats, terrestrial mammals and insects (Robinson et al. , 2009). Reduced precipitation, increasing temperatures and desertification have caused a large number of fruit bats to migrate from their ecological niches in the equatorial rain forest to other areas where environmental conditions are more favorable for survival (Omolekeet al. , 2016).

Actually, the world is facing climate change and this has been for decades. The effects that climate change is having on wildlife populations are of increasing interest to ecologists (Adams and Hayes, 2008). The survival of species and integrity of terrestrial ecosystems are threatened by the climate change. To adapt to climate change, a thorough knowledge of its impact on plant and animal species is of crucial importance (Fandohan et al. , 2013). Recent research increasingly shows that climate change will significantly affect biodiversity and species distribution. With the most recent research, one of the hypotheses put forward is that in Africa, 25 to $42 \%$ of plant and animal species could be threatened and could thus lose up to $90 \%$ of their geographical distribution areas by 2085 if global warming exceeds 1.5 to 2.5 degrees Celsius (Busby et al. , 2012). Elithet al. (2010) and Guisan and Thuiller (2005) have enumerated modeling tools among which species distribution models. The utilization of species distribution models is spreading out (Martínez-Meyer et al. , 2004; Papes and Gaubert, 2007; Tsoar et al. , 2007; Jenningset al. , 2013). Species distribution models are numerical tools that provide potential distribution, aid in conservation planning and their project future behaviour in response to environment changes (Peterson, 2003, 2006; Thorn et al. , 2009; Barve et al. , 2011). The main objective of mapping spatial distribution of vectors and reservoirs of diseases is to manage diseases impacts by providing geographic information that enables decision-makers to make evidence-based decisions (Benedict et al. , 2007; Lindsay et al. , 2010) or the planning and targeting of surveillance and interventions (Dicko et al. , 2014). An additional motivation of the wide use of species distribution models techniques comes from the high impacts of diseases on humans, animal and plant and the fact that environmental drivers play a major role in their emergence (Chaveset al. , 2008; Jones et al. , 2008; Pautasso et al. , 2010). During last decade, modeling techniques have been developed to model ecological distribution. Maximum entropy (MaxEnt) approaches have recently been introduced and used by many research work and have shown to be very successful tool (Peterson et al. , 2007; Elith et al. , 2010). Several studies comparing species distribution modeling techniques indicated that MaxEnt modeling (Phillips et al. , 2006) performed as well or better than the other techniques (Elith et al. , 2006, 2011; Hernández et al. , 2006; Phillips et al. , 2006; Phillips and Dudík, 2008; Baldwin, 2009). As such, considering the new features integrated in the new release of MaxEnt program (Phillips, 2017), it should be a very useful and accurate tool for delineating species distributions.

Modelling H. monstrosus, M. torquata and E. franquetispecies distribution using MaxEnt modelling technique could essentially improve our understanding of the spatial distribution of current and future risk of increased or decreased distribution of these species.

In order to better understand the nature of Ebola viruses risk, this study aims to define areas of DR Congo where zoonotic transmission of Ebola viruses can occur, currently and in the future. Thus, by studying the spatial distribution of $H$. monstrosus, $M$. torquata and $E$. franqueti, potential reservoirs of the Ebolavirus, this study seeks to identify their current and future favorable and suitable areas in DR Congo. This study illustrates the climate change risk assessment of the spatial distribution of these species according to the climate scenario in 2050 (2041 - 2060) and 2070 (2061 - 2080), and to seek attention of their future favourable habitats in DR Congo.

\section{MATERIALS AND METHODS}

\section{Occurrence records}

In this study, due to the lack of sufficient occurrence data of DR Congo, we used occurrence data from the entire African continent to build the model and make the prediction only in DR Congo. The geographical 
coordinates (longitude and latitude) of $H$. monstrosus, $M$. torquata and E. franqueti were collected online from the GBIF database (http://www.gbif.org). All occurrence records were checked for accuracy in ArcGIS prior to use. The data were quality controlled in order to eliminate or remove suspicious or duplicate records (Lobo et al. , 2008; Warton and Shepherd, 2010; Stigall, 2012). A total of 123 observation points of $H$. monstrosus , $79 \mathrm{M}$. torquata and $201 \mathrm{E}$. franqueti in Africa continent were used for the modelling. In DR Congo, only 10 occurrence records of $E$. franqueti, 9 of $H$. monstrosus and 7 of $M$. torquata were found. It was not possible to model the distribution of these species in DR Congo using only these data, since they were insufficient. This is why we came up with the idea of using data from all of Africa's occurrence records to build the models and do prediction only on the extent of DR Congo. The map representing the points of occurrence is illustrated in Figure 1.

\section{Environmental variables}

In this study, we used elevation data together with bioclimatic data. Elevation data (Digital Elevation Model) was obtained from USGS database (https://earthexplorer.usgs.gov) and the current and future climate data were collected from WorldClim database (http://www.worldclim.org) and used to build the species distribution model in order to find the suitable areas for H. monstrosus, M. torquata and E. franqueti . Bioclimatic data collected from the WorldClim database are obtained from interpolations of monthly averages of precipitation and temperature taking into account climate data collected over long periods of time (Fick and Hijmans, 2017). The 19 bioclimatic variables (bio1; Mean Annual Temperature, bio2: Mean Diurnal Range, bio3: Isothermality, bio4: Temperature Seasonality, bio5: Maximum Temperature of Warmest Month, bio6: Min Temperature of Coldest Month, bio7: Annual Temperature Range, bio8: Mean Temperature of Wettest Quarter, bio9: Mean Temperature of Driest Quarter, bio10: Mean Temperature of Warmest Quarter, bio11: Mean Temperature of Coldest Quarter, bio12: Annual Precipitation, bio13: Precipitation of Wettest Month, bio14: Precipitation of Driest Month, bio15: Precipitation Seasonality, bio16: Precipitation of Wettest Quarter, bio17: Precipitation of Driest Quarter, bio18: Precipitation of Warmest Quarter and bio19: Precipitation of Coldest Quarter) have a high biological significance, are widely used to explain the adaptation of species to environmental factors and have been widely used in modelling species distribution. In the Worldclim database, the current period represents interpolations from monthly average precipitation and temperature data collected from 1950 to 2000. All environmental variables were in raster format with a 2.5-arc minute resolution ([?] $\left.4.5 \mathrm{~km}^{2}\right)$. The 20 environmental variables (19 bioclimatic variables and Elevation) were subject to the correlation test using the $\mathrm{R}$ software (R Development Core Team, 2018). Consequently, Pearson correlation coefficients belonging to the interval $]-0.8,0.8[(|\mathrm{r}|<0.8)$ with only a subset of variable were included in order to eliminate the problem of collinearity in environmental predicators (Elith et al. , 2010).

We used eleven environmental variables in this model prediction. This was after assessing for collinearity in the model and removing all the collinear variables. The result from the correlation analysis identified eleven bioclimatic variables and elevation as contributing to the environmental variation across the study area: Precipitation of Driest Quarter (bio17), Annual Temperature Range (bio7), Elevation, Mean Diurnal Range (bio2), Precipitation Seasonality (bio15), Precipitation of Warmest Quarter (bio18), Precipitation of Wettest Quarter (bio16), Mean Temperature of Wettest Quarter (bio8), Mean Temperature of Warmest Quarter bio10), Min Temperature of Coldest Month (bio6), Precipitation of Coldest Quarter (bio19) and Mean Temperature of Driest Quarter (bio9).

To determine what the distribution of these species might be in the future and thus assess the potential impacts of climate change on their distribution, we used the model built from current data to make the prediction using bioclimatic future prediction data obtained using the future HadGEM-CC projection model. The impacts of climate change strategies on greenhouse gas emissions are considered more in the RCPs scenarios, and the projection of future climate change is more scientifically described. RCP4.5 (medium greenhouse gas emission scenario) and RCP8.5 (maximum greenhouse gas emission scenario) for the near future: 2050 (2041 - 2060) and the middle century: 2070 (2061 - 2080) were selected for the future model prediction of $H$. monstrosus, $M$. torquata and E. franqueti distribution in DR Congo.

\section{Distribution modeling}


We used MaxEnt software (Phillips et al. , 2006, 2017) to build model and predict suitable habitat distribution of H. monstrosus, M. torquata and E. franqueti in DR Congo. We used Presence-only data to model the suitable habitat of the three species. The MaxEnt model was built as a function of environmental variables, and it is consistently among the highest performing species distribution models (SDMs) (Bradie and Leung, 2017). Response curves indicate the relationships between climatic variables, and the predicted probability of the presence of each species was determined by MaxEnt. The percent contribution and permutation importance of environmental variables were calculated, and jackknife procedures were executed in MaxEnt. These analysis methods are all useful to measure the importance of the environmental variables. MaxEnt estimates the probability a species will be present based on presence records and randomly generates background points by finding the maximum entropy distribution. An estimate of habitat suitability for a species was exported from MaxEnt, and its range generally varied from 0 (lowest) to 1 (highest). For each species we ran 100 submodels each trained to a randomly selected bootstrap of the occurrence dataset. Prediction map form each submodel has been generated in order to calculate the mean prediction and standard deviation of each pixel for each species. Model predictions were imported into a geographic information system (GIS), and maps were generated using ArcMap 10.6. Five arbitrary categories of habitat suitability for the three species of bats were defined as not suitable habitat $(0.00-0.05)$, slightly suitable habitat $(0.05-0.25)$, moderately suitable habitat $(0.25-0.50)$, suitable habitat $(0.50-0.75)$ and highly suitable habitat $(0.75$ 1.00) based on predicted habitat suitability.

In this study, the ROC curve method was utilized to assess the model's explanatory power (Peterson et al. , 2007). The AUC (area under roc curve) is an effective threshold-independent index that can evaluate a model's ability to discriminate presence from absence (or background). For reducing the bias of estimation, jackknife method has been used. This method can estimate parameters and adjust the deviation without assumptions of distribution probability. In SDM, the jackknife method was used to analyze the effects of environmental variables on model results to choose dominant factors. The specific process involves:

1. Calculating the training gain for the model with only variable. Higher training gain indicates that the variable has high prediction power and contributes greatly to species distribution;

2. Calculating the training gain for the model without a specific variable and analyzing the correlation between the removed variable and the omission error. If the removal of an environmental variable leads to a significant increase in the omission error, it indicates that the variable has a significant effect on the model's prediction;

3. Calculating the training gain for the model with all variables.

\section{RESULTS}

\section{Model performance and contributions of variables}

In this study, from the ROC curves, AUC values were used to evaluate the performance of the MaxEnt models. Many studies showed that an AUC of high values led to better results that significantly differed from the random predictions. The accuracy of prediction of $H$. monstrosus, $M$. torquata and $E$. franqueti during the current period was found to be excellent (Mean AUC [?] 0.96, Figure 2) according to the identified evaluation criteria.

Among the environmental variables, the Precipitation of the driest quarter (43.1\% - $64.3 \%)$ played major role in the spread of $H$. monstrosus, $M$. torquata and E. franqueti (Table 1 and Figure 3). In addition, the Temperature Annual Range played also a major role in the spread of E. franqueti $(12.7 \%)$ and $H$. monstrosus $(14.6 \%$ ) while the Precipitation of Coldest Quarter has also showed to play also a major role in the spread of M. torquata (36.4\%) and H. monstrosus (10.4\%).

Tableau 1: Estimates of contribution and permutation importance of environmental variables in MaxEnt modeling

\begin{tabular}{llllll}
\hline Variables & Code & E. franqueti & E. franqueti & H. monstrosus & H. monstrosus \\
\hline & & PC & PI & PC & PI
\end{tabular}




\begin{tabular}{llllll}
\hline Variables & Code & E. franqueti & E. franqueti & H. monstrosus & H. monstrosus \\
\hline Mean Diurnal Range & data_wc_bio02 & 4.4 & 2 & 9.2 & 1.8 \\
Minimum Temperature of Coldest Month & data_wc_bio06 & 1.3 & 3.3 & 2.8 & 2.4 \\
Temperature Annual Range & data_wc_bio07 & $\mathbf{1 2 . 7}$ & 35.1 & $\mathbf{1 4 . 6}$ & 69.1 \\
Mean Temperature of Wettest Quarter & data_wc_bio08 & 1.8 & 23 & 0.0 & 0.4 \\
Mean Temperature of Driest Quarter & data_wc_bio09 & 0.6 & 2.9 & 0.1 & 1.2 \\
Mean Temperature of Warmest Quarter & data_wc_bio10 & 1.7 & 1.3 & 1 & 4.8 \\
Precipitation Seasonality & data_wc_bio15 & 3.1 & 7.2 & 0.9 & 1.6 \\
Precipitation of Wettest Quarter & data_wc_bio16 & 2 & 1.6 & 1.8 & 1.9 \\
Precipitation of Driest Quarter & data_wc_bio17 & $\mathbf{6 4 . 3}$ & 10.1 & $\mathbf{4 7 . 8}$ & 6.8 \\
Precipitation of Warmest Quarter & data_wc_bio18 & 2.3 & 5.8 & 9.7 & 7.4 \\
Precipitation of Coldest Quarter & data_wc_bio19 & 1.3 & 5.3 & $\mathbf{1 0 . 4}$ & 1.5 \\
Elevation & data_elevation & 4.5 & 2.4 & 1.6 & 1.1 \\
\hline
\end{tabular}

PC : Percent contribution ; PI : Permutation importance

\section{Response of variables to suitability}

Response curves indicated the relationships between environmental variables and the predicted probability of the presence of $H$. monstrosus, M. torquata and E. franqueti . As stated above, the spread of E. franqueti has showed to be mostly influenced by the precipitation of the driest quarter and the temperature annual range. For this species, the occurrence probability is high if the temperature annual range is less than $8^{\circ} \mathrm{C}$. The occurrence probability becomes almost zero from an temperature annual range of $20^{\circ} \mathrm{C}$ while $E$. franquetihas shown to prefer area where the precipitation of driest quarter goes from $100 \mathrm{~mm}$ to $300 \mathrm{~mm}$. $H$. monstrosus has also shown to have ecological preferences that are close to those of $E$. franquetibut has shown, furthermore, to be influenced by Precipitation of coldest quarter. The occurrence probability has shown to be high in area where precipitation of coldest quarter is greater than 200. M. torquatahas shown to be influenced the most by the Precipitation of Driest Quarter and the Precipitation of Coldest Quarter. For this species, the increase of the Precipitation of Driest quarter and the precipitation of coldest quarter increase the probability of occurrence. The most suitable area for $M$. torquata are the ones where Precipitation of the driest quarter is greater than $140 \mathrm{~mm}$ and Precipitation of the coldest quarter is greater than $900 \mathrm{~mm}$ (see Figure 4).

Predicting the current distribution of E. franqueti, H. monstrosus and M. torquata in DR Congo

The result showed that the area from latitude $-5^{\circ}$ to $5^{\circ}$ and from longitude $17^{\circ}$ to $30^{\circ}$ are the primary potential suitable region of E. franqueti, H. monstrosus and $M$. torquata in DR Congo (see Figure 5). Current distribution models show that the most favourable areas for $E$. franqueti are located in the territories of Faradje, Aru, Mahagi, Djugu, Irumu, Beni, Lubero, Walikale, Rutshuru, Masisi, Kalehe, Kabare, Idjwi and Walungu. The areas favourable to $H$. monstrosus are the same as those of $E$. franqueti, in addition to which the areas located in the territories of Ango, Bambesa, Polo, Niangara, Watsa, Mambasa, and Punia must be added. Unlike these two species, $M$. torquata seems to find comfort in the territories located in the far north of the DR Congo, particularly in the territories of Zongo, Bosobolo, Gemena, Businga, Mobayi-Mbongo, Yakoma, Bondo, Ango, Bambesa, Niangara, Dungu, Faradje, Aru and Djugu. A small area favourable to $M$. torquata is also located in North Kivu province, specifically in the territories of Walikale, Rutshuru and Masisi. Overall, the ecological niche of these three species is the Eastern and Northeastern regions of DR Congo.

Predicting the future distribution of $E$. franqueti, H. monstrosus and $M$. torquata in DR Congo 2050s distribution 
Under future climate scenario RCP 4.5 and RCP 8.5 (Figure 6), the suitable area of the three species will be decreasing showing that their distribution will be strongly affected. These figures show that, even in both 2050s climate scenarios the suitable of the three species will decrease, the climate of RCP 8.5 will affect the most the distribution of the three species. In this scenario, the suitable area will decrease more than in the climate scenario of RCP 4.5. Overall, highly suitable area will be concentrated in the Kivu provinces. Overall, the areas favourable to these three bat species will be located in the territories of Mahagi, Djugu, Rutshuru, Masisi, Punia, Shabunda, Kelehe, Kabare, Idjwi, Walungu, Mwenga and Uvira.

\section{0s distribution}

As stated above for the 2050s distribution of $H$. monstrosus , M. torquata and E. franqueti, in all considered future climate scenario, their suitable area will decrease severally. In 2070s, the high suitable area of $H$. monstrosus , $M$. torquata and E. franqueti will be essentially located in the Kivu provinces in DR Congo (see Figure 7). With the RCP 4.5 scenario, in general, the favourable areas for these three species will be located mainly in the territories of Mahagi, Djugu, Beni, Lubero, Rutshuru, Walikale, Masisi, Kalehe, Idjwi, Kabare, Walungu, Mwenga and Uvira. However, these areas will be greatly reduced with the RCP 8.5 scenario whereby areas favourable to these species are mainly located in the territories of Beni, Lubero, Walikale, Rutshuru, Kalehe, Idjwi, Kabare, Walungu, Mwenga and Uvira.

\section{DISCUSSION}

\section{Current distribution of bat species}

According to Peterson et al . (2004), african Ebola virus reservoirs would be distributed principally in evergreen broadleaf forest (rainforest) and the main focus of the geographic distribution of the reservoirs would be in the Congo Basin. this is all the more true since our results prove that the distribution areas of the three bat species in DR Congo correspond roughly to the areas covered by Tropical and subtropical moist broadleaf forests. With the results obtained in this study it is clear that the current ecological niche of the three bat species under study is the entire part from the centre to the north of DR Congo. The most favourable environments for these species are mainly the eastern and northeastern parts, border areas with southern Sudan and Uganda, two countries that have already recorded cases of Ebola hemorrhagic fever epidemics. Bats are hypothesized to be reservoirs for filoviruses among which Ebola virus. They have been identified as an important driver of outbreaks of filovirus diseases (Fiorillo et al., 2018). Nyakarahuka et al. (2017) found that their distribution tends to correlate with that of filovirus predicted niches. Clearly, with the results of this work, the populations that appear to be most at risk are those in the areas listed above. This would be all the more true since almost all cases of Ebola in the human population in DR Congo have been recorded in these areas (from the centre to the north of DR Congo). Pigott et al. (2014) found that the vast majority of people living in suitable area of the three bat species live in rural areas and populations of DR Congo are among those the most at risk of experiencing Ebola outbreak. In addition, almost all outbreaks of Ebola in the human population have been recorded in rural areas.

\section{Implications of the future distributions of bat species on the Ebolavirus disease risk}

In this study, we found that in the future, the areas favourable to the distribution of these species will decrease considerably in terms of available surface areas. The models of future distribution of these three bat species show that the favourable environments for these species will be mainly located in the former Kivu province and the current Ituri province. These regions represent the part of the DR Congo located in the Albertine Rift. Nyakarahuka et al. (2017) suggested the Albertine Rift of East Africa to remain under heightened surveillance especially now that oil exploration will be taking place bringing an invasion of virgin lands by humans and interaction of wildlife and humans. Based on our findings, we do agree with them because in DR Congo bats will find in the future their more suitable habitat in area located in the said rift. They noted also that in this region, several other national parks as well as several forest reserves all of which harbor various species of bats and other possible reservoirs of filoviruses. The eating habits and socioeconomic status of the populations are determinant in the emergence of Ebola viruses. Increasing human encroachment and certain cultural practices sometimes linked with poverty, such as bushmeat hunting, result in increasing exposure 
of humans to animals which may harbour diseases including Ebola (Daszaket al. , 2000; Wolfe et al. , 2005, 2007). Indeed, bushmeat represents a natural reserve that is exploited in the absence of financial means for purchasing animal proteins. Bushmeat is considered a daily food source in rural areas. The major challenge for accessing protein sources is of economic nature. The inaccessibility of domestic animal flesh also renders the bushmeat consumption particularly important to households because it is free and they can have all the parts of the animal (Dindé et al. , 2017). Because previous outbreaks in Central Africa have been linked to reports of bushmeat consumptions and deaths of wildlife (Leroy et al. , 2004), many hypotheses have been put forward to suggest wildlife such as bats, primates, and antelopes as possible sources of infection (Osterholmet al. , 2015; Nyakarahuka et al. , 2017).

\section{Insights on variables contributions}

Variable contribution assessment showed that precipitation variables played the most important role in the distribution models. Indeed, in this study, the Precipitation of the driest quarter $(43.1 \%-64.3 \%)$ played major role in the spread of $H$. monstrosus, $M$. torquata and $E$. franqueti (Table1 and Figure 3 ). In addition, the Temperature Annual Range played also a major role in the spread of E. franqueti $(12.7 \%)$ and $H$. monstrosus $(14.6 \%)$ while the Precipitation of Coldest Quarter has also showed to play also a major role in the spread of $M$. torquata $(36.4 \%)$ and $H$. monstrosus (10.4\%). The importance of precipitation and moderate to high temperature was highlighted by (Peterson et al. , 2004) when they modeled filovirus distribution in Africa. Rainfall is important for the obvious reason that it provides water which is very important for bats survival (Adams and Hayes, 2008; Russo et al. , 2012). Rainfall also provides for the development of fruiting trees that provide roosting areas for bats as well as food for fruit bats. Because the risk of dehydration is the greatest physiological threat to life on land, drinking water is a fundamental resource for all terrestrial animals (Knut, 1997). Due to their peculiar morphology and physiology, bats often face the risk of dehydration. Much water is lost through their body surface, especially via the respiratory system and the extensive surfaces of wing membranes (Chew and White, 1960; Thomas and Cloutier, 1992). The importance of water availability has been emphasized in studies addressing the impact of climate change on bats (Adams and Hayes, 2008) as well as in those modelling bat distribution patterns (Rainho et al. , 2010). In addition, DR Congo is endowed with many water bodies and several rainforests; this could be why the areas favourable to the distribution of bats cover a very large part of the country.

\section{Uncertainties related to the models}

The models we obtained have shown to be accurate. The Area Under the Curve (AUC) proportion was high, about 0.96 . Therefore, the models are considered to perform better than random. Accurate predictive models are of particular importance for effective and adaptive management and conservation, ecological research and prediction. Thus, predictive accuracy is an important feature that is sought in species distribution modeling (Jarnevich et al. , 2015). Although these models have shown to be accurate, certain reasons may prevent complete reliance on their predictions. Variation in the output of SDMs may arise due to errors and uncertainties related to the SDMs themselves, characteristics of species life histories and future climate models (Beaumont et al. , 2008).

There is a debate criticizing the prediction results of these models. What is really modeled, the fundamental niche or the realized niche? There is ongoing debate in the ecological literature regarding exactly what these distributions represent (Warren and Seifert, 2011; McInerny and Etienne, 2013; Warren et al. , 2013). The lack of consensus on how distribution modelling relates to niche concepts is probably caused not only by inconsistency of niche definitions, but also the variability in data, methods and scale across studies (Araújo and Guisan, 2006; Soberón, 2007). Some studies have suggested that, if the realized niche is the subset of abiotic environmental space to which a species is restricted by biotic interactions (Hutchinson, 1957), then, by definition, known occurrence points used to generate distribution models represent the realized niche (Phillips et al. , 2006). Fundamental or environmental niches are only considered to be approximated by distribution models when occurrence data are drawn from a broad geographical extent (relative to the total range of the species in question) (Phillips et al. , 2006). Other studies caution against such generalizations (Elith and Leathwick, 2009), arguing that the different niches quantified using observed occurrences of species reflect 
an unknown conjunction of the environmental niches of the species, the biotic interactions they experience and the habitats available to species and colonized by them (Soberón, 2007).

There are uncertainties that would result from biases in the data used to develop the models. Indeed, the uncertainty associated with ecological data is great challenge in species distribution modeling. It must be accounted for if results are to be appropriately interpreted or if they are the basis of a decision-making process (Elith et al. , 2002; Barry and Elith, 2006). Several factors can affect the precision of SDMs among which we can find factors such as spatial autocorrelation, data sampling bias, varying detection probabilities (between species and observers), non-representative data prevalence, mismatched scales data misregistration or the failure to incorporate critical habitat variables in the models that damage severally the quality of data to be used in modeling (Pearce et al., 2001; Boyce et al. , 2002; Kadmonet al. , 2003; Gu and Swihart, 2004; Barry and Elith, 2006; Johnson and Gillingham, 2008; Osborne and Leitão, 2009). In addition, the ecological characteristics of the species to be modeled can also have an effect on its SDMs' precision (McPherson and Jetz, 2007; Franklin et al. , 2009). Imperfect detection can, for instance, mislead inference about drivers and extent of species distributions, quantifications of diversity and conclusions about environmental changes (Guillera-Arroita, 2017). This is a major weakness of these models because most surveys of natural populations, including opportunistic surveys that produce presence only observations, are prone to imperfect detection (Yoccoz et al. , 2001; Chen et al. , 2013). Furthermore, Dorazio (2012) and Lahoz-Monfort et al. (2014) have shown that failure to account for imperfect detectability in models of Presence-only data induces bias in estimates of SDMs. Observed counts of abundance are biased when individuals are imperfectly detected and this lead to biased occurrence probabilities and stated occupancy (Royleet al., 2005). In spite of this, some researchers have recommended ignoring this challenge (Johnson and Gillingham, 2008; Banks-Leite et al. , 2014; Stephens et al. , 2015). Hence, there is no consensus about the importance of accounting for this sort of measurement error in SDMs (Guélat and Kéry, 2018).

Another limitation of SDMs is that they do not correct for sampling bias. Unrepresentative presence only locations of the region of interest induce biased SDMs' estimates (Phillips et al., 2009; Yackulicet al. , 2013). Accounting for the effects of geographical sampling bias in the acquisition of data can be critical to the accuracy of SDMs made using presence only data (Phillips et al. , 2009). Most of surveys of natural populations, including opportunistic surveys that produce presence only data are prone to sampling bias. For instance, if survey locations are selected based on their accessibility or convenience induce bias in datasets. Most of time, presence only data are collected based on accessibility of sampled locations. Thus, samples are located near urban settlements, rivers and roads instead of being collected systematically or randomly. Hence, their sample localities are not representative of the real range of environmental conditions in which the species of interest occurs (Reddy and Dávalos, 2003; Kadmonet al. , 2004). Such geographical sampling bias is a characteristic of most specimen locality data available from open access data portals (Hortal et al. , 2008). Failure to correct for geographical sampling bias can result in a SDMs that reflects sampling effort rather than the true distribution of a species (Phillips et al. , 2009).

Species occurrence data suffer from the disadvantage of containing the problem of spatial auto-correlation. We cannot afford to ignore this bias in the modeling of species distribution. Species distribution models implicitly assume that the geographical data points for species records are independent and the environmental layers used as hypothetical predictive variables and associated to the geographical records of species also show problems of spatial auto-correlation (Segurado et al. , 2006; Cruz-Cárdenas et al. , 2014). The spatial autocorrelation caused by colonized sites tending to cluster around initial invasion foci inflate not only model accuracy, but also the estimated explanatory power of environmental predictors (particularly when these are distally related to the requirements of the focal species) and underestimate uncertainty in model parameters (Dormann, 2007). Disregard and not avoid spatial auto-correlation has consequences such as incurring in biased model and hence inflate type I errors (Dormann, 2007; Cruz-Cárdenas et al. , 2014). Therefore, where biological or population processes induce substantial auto-correlation in the species distribution, and this is not modeled, model predictions will be inaccurate.

Another source of uncertainty in the future model is related to the climate model used. Climate models 
are currently the best tools we have for simulating future climate scenarios. However, variation within and among alternate climate models poses problems for end users trying to identify optimal models from which to obtain simulations (Martinez-Meyer, 2005; Perkins et al. , 2007). To date there is no clear guidance on how to select the most appropriate simulations for a given application (Beaumont et al. , 2008). Species distribution models have been very criticized for their weaknesses in predicting climate change impact on the geographic species dispersion. Among these weaknesses, we can cite: uncertainties related to the models used, difficulties in ecological interactions setting, individual idiosyncratic responses of the species to climate change, limitations of species-specific dissemination, plasticity of physiological limits and disseminating agents responses (Fandohan et al. , 2013).

\section{CONCLUSION}

Although the models used and their predictions are highly criticized, they nevertheless shed light on the management of current and future risks of Ebola epidemics by mapping the areas where most attention and prevention measures should be focused. Species distribution models are useful tools for, among other things, informing the conservation management of wildlife and their habitats under a rapidly changing climate. They can provide decision makers with information about the likely degree of change in a species climatic domain and geographic distribution. The MaxEnt model is potentially useful for forecasting the future adaptive distribution of the three bat species under climate change, and it provides important guidance for comprehensive management of the Ebolavirus risk. The results obtained in this study showed that climate change will significantly reduce the areas favourable to the distribution of these three species, reducing the risk they represent in the emergence of the Ebola epidemic. However, since not all reservoirs of the Ebolavirus are yet well identified and the other components of the emergence of the Ebola epidemic have not been taken into account in this study, it will not be possible to say that the effects of climate change will reduce the risk associated with Ebola. But it is still possible that this may be the case. It is therefore necessary for future work to take into account these components to assess the effects of climate change on the risk of Ebola occurrence in DR Congo.

\section{ACKNOWLEDGMENTS}

Authors acknowledge the Université Evangélique en Afrique for manifold support to this work through the University project on improvement of research and teaching quality funded by Pain pour le Monde (Project A-COD-2018-0383).

\section{CONFLICT OF INTEREST}

The authors declare no conflicts of interest.

\section{AUTHOR CONTRIBUTIONS}

Yannick Mugumaarhahama : Conceptualization (lead); Data curation (lead); Formal analysis (lead); Writing-original draft (lead); Writing-review \& editing (lead). Marcellin Cuma Cokola : Conceptualization (equal); Data curation (equal); Formal analysis (supporting); Writing-original draft (equal); Writingreview \& editing (equal). Arsene Ciza Mushagalusa : Conceptualization (supporting); Data curation (supporting); Formal analysis (equal); Writing-original draft (supporting); Writing-review \& editing (supporting). Nadege Cizungu Cirezi : Conceptualization (supporting); Data curation (supporting); Formal analysis (supporting); Writing-original draft (supporting); Writing-review \& editing (supporting). Espoir Mukengere Bagula : Conceptualization (supporting); Data curation (supporting); Formal analysis (supporting); Writing-original draft (supporting); Writing-review \& editing (supporting). Katcho Karume : Conceptualization (supporting); Data curation (supporting); Formal analysis (supporting); Writing-original draft (supporting); Writing-review \& editing (supporting). Gustave Nachigera Mushagalusa : Conceptualization (supporting); Data curation (supporting); Formal analysis (supporting); Writing-original draft (supporting); Writing-review \& editing (supporting).

\section{DATA AVAILABILITY STATEMENT}


The data used in this study were downloaded from open access data bases www.gbif.org. The doi's of the downloads used in this study are Epomops franqueti download https://doi.org/10.15468/dl.gngooy ; Myonycteris torquatadownload https://doi.org/10.15468/dl.yclrwy ; Hypsignathus monstrosus download https://doi.org/10.15468/dl.xmmhnk.

\section{REFERENCES}

Adams, R. A. and Hayes, M. A. (2008) 'Water availability and successful lactation by bats as related to climate change in arid regions of western North America', Journal of Animal Ecology , 77(6), pp. 11151121. doi: $10.1111 / \mathrm{j} .1365-2656.2008 .01447 . x$.

Araujo, M. B. and Guisan, A. (2006) 'Five (or so) challenges for species distribution modelling', Journal of Biogeography , 33(10), pp. 1677-1688. doi: 10.1111/j.1365-2699.2006.01584.x.

Baldwin, R. A. (2009) 'Use of maximum entropy modeling in wildlife research', Entropy , 11(4), pp. 854-866. doi: $10.3390 / \mathrm{e} 11040854$.

Banks-Leite, C. et al. (2014) 'Assessing the utility of statistical adjustments for imperfect detection in tropical conservation science', Journal of Applied Ecology , pp. 849-859. doi: 10.1111/1365-2664.12272.

Barry, S. and Elith, J. (2006) 'Error and uncertainty in habitat models', Journal of Applied Ecology , 43(3), pp. 413-423. doi: 10.1111/j.1365-2664.2006.01136.x.

Barve, N. et al. (2011) 'The crucial role of the accessible area in ecological niche modeling and species distribution modeling',Ecological Modelling , 222(11), pp. 1810-1819. doi: 10.1016/j.ecolmodel.2011.02.011.

Bausch, D. G. and Schwarz, L. (2014) 'Outbreak of Ebola Virus Disease in Guinea: Where Ecology Meets Economy', PLoS Neglected Tropical Diseases , 8(7), p. e3056. doi: 10.1371/journal.pntd.0003056.

Beaumont, L. J., Hughes, L. and Pitman, A. J. (2008) 'Why is the choice of future climate scenarios for species distribution modelling important?', Ecology Letters , 11(11), pp. 1135-1146. doi: 10.1111/j.14610248.2008.01231.x.

Benedict, M. Q. et al. (2007) 'Spread of The Tiger: Global Risk of Invasion by The Mosquito Aedes albopictus', Vector-Borne and Zoonotic Diseases , 7(1), pp. 76-85. doi: 10.1089/vbz.2006.0562.

Boyce, M. S. et al. (2002) 'Evaluating resource selection functions', Ecological Modelling , 157(2-3), pp. 281-300. doi: 10.1016/S0304-3800(02)00200-4.

Bradie, J. and Leung, B. (2017) 'A quantitative synthesis of the importance of variables used in MaxEnt species distribution models', Journal of Biogeography , 44(6), pp. 1344-1361. doi: 10.1111/jbi.12894.

Busby, J. W. et al. (2012) 'Locating Climate Insecurity: Where Are the Most Vulnerable Places in Africa?', in Scheffran, J. et al. (eds) Climate Change, Human Security and Violent Conflict: Challenges for Societal Stability . Berlin, Heidelberg: Springer Berlin Heidelberg, pp. 463-511. doi: 10.1007/978-3-642-28626-1_23.

Chaves, J. et al. (2008) 'Land management impacts on runoff sources in small Amazon watersheds', Hydrological Processes , 22(12), pp. 1766-1775. doi: 10.1002/hyp.6803.

Chen, G. et al. (2013) 'Imperfect detection is the rule rather than the exception in plant distribution studies', Journal of Ecology , 101(1), pp. 183-191. doi: 10.1111/1365-2745.12021.

Chew, R. M. and White, H. E. (1960) 'Evaporative water losses of the pallid bat', Journal of Mammalogy , 41(4), pp. 452-458. doi: 10.2307/1377532.

Cruz-Cardenas, G. et al. (2014) 'Potential species distribution modeling and the use of principal component analysis as predictor variables.', Revista Mexicana de Biodiversidad , 85(1), pp. 189-199. doi: $10.7550 / \mathrm{rmb} .36723$. 
Daszak, P., Cunningham, A. A. and Hyatt, A. D. (2000) 'Emerging infectious diseases of wildlife - Threats to biodiversity and human health', Science, 287(5452), pp. 443-449. doi: 10.1126/science.287.5452.443.

Dicko, A. H. et al. (2014) 'Using species distribution models to optimize vector control in the framework of the tsetse eradication campaign in Senegal', Proceedings of the National Academy of Sciences of the United States of America , 111(28), pp. 10149-10154. doi: 10.1073/pnas.1407773111.

Dinde, A. O. et al. (2017) 'Response to the Ebola-related bushmeat consumption ban in rural Cote d'Ivoire', Agriculture and Food Security, 6(28), pp. 1-9. doi: 10.1186/s40066-017-0105-9.

Dorazio, R. M. (2012) 'Predicting the Geographic Distribution of a Species from Presence-Only Data Subject to Detection Errors',Biometrics , 68(4), pp. 1303-1312. doi: 10.1111/j.1541-0420.2012.01779.x.

Dormann, C. F. (2007) 'Effects of incorporating spatial autocorrelation into the analysis of species distribution data', Global Ecology and Biogeography , 16(2), pp. 129-138. doi: 10.1111/j.1466-8238.2006.00279.x.

Elith, J. et al. (2006) 'Novel methods improve prediction of species' distributions from occurrence data', Ecography , 29(2), pp. 129-151. doi: 10.1111/j.2006.0906-7590.04596.x.

Elith, J. et al. (2011) 'A statistical explanation of MaxEnt for ecologists', Diversity and Distributions , 17(1), pp. 43-57. doi: 10.1111/j.1472-4642.2010.00725.x.

Elith, J., Burgman, M. A. and Regan, H. M. (2002) 'Mapping epistemic uncertainties and vague concepts in predictions of species distribution', Ecological Modelling , 157(2-3), pp. 313-329. doi: 10.1016/S03043800(02)00202-8.

Elith, J., Kearney, M. and Phillips, S. (2010) 'The art of modelling range-shifting species', Methods in Ecology and Evolution , 1(4), pp. 330-342. doi: 10.1111/j.2041-210X.2010.00036.x.

Elith, J. and Leathwick, J. R. (2009) 'Species Distribution Models: Ecological Explanation and Prediction Across Space and Time',Annual Review of Ecology, Evolution, and Systematics , 40(1), pp. 677-697. doi: 10.1146/annurev.ecolsys.110308.120159.

Fandohan, B. et al. (2013) 'Impact des changements climatiques sur la repartition geographique des aires favorables a la culture et a la conservation des fruitiers sous-utilises: Cas du tamarinier au Benin', Biotechnology, Agronomy and Society and Environment, 17(3), pp. 450-462. doi: 10.1179/146531207225022302.

Feldmann, H. and Geisbert, T. W. (2011) 'Ebola haemorrhagic fever', The Lancet , 377(9768), pp. 849-862. doi: $10.1016 / \mathrm{S} 0140-6736(10) 60667-8$.

Fick, S. E. and Hijmans, R. J. (2017) 'WorldClim 2: new 1km spatial resolution climate surfaces for global land areas', International Journal of Climatology, 37(12), pp. 4302-4315.

Fiorillo, G., Bocchini, P. and Buceta, J. (2018) 'A Predictive Spatial Distribution Framework for FilovirusInfected Bats', Scientific Reports, 8(1), pp. 1-13. doi: 10.1038/s41598-018-26074-4.

Franklin, J. et al. (2009) 'Effect of species rarity on the accuracy of species distribution models for reptiles and amphibians in southern California', Diversity and Distributions , 15(1), pp. 167-177. doi: 10.1111/j.14724642.2008.00536.x.

Groseth, A., Feldmann, H. and Strong, J. E. (2007) 'The ecology of Ebola virus', Trends in Microbiology , 15(9), pp. 408-416. doi: 10.1016/j.tim.2007.08.001.

Gu, W. and Swihart, R. K. (2004) 'Absent or undetected? Effects of non-detection of species occurrence on wildlife-habitat models', Biological Conservation, 116(2), pp. 195-203. doi: 10.1016/S0006-3207(03)00190-3.

Guelat, J. and Kery, M. (2018) 'Effects of spatial autocorrelation and imperfect detection on species distribution models', Methods in Ecology and Evolution, 9(6), pp. 1614-1625. doi: 10.1111/2041-210X.12983. 
Guillera-Arroita, G. (2017) 'Modelling of species distributions, range dynamics and communities under imperfect detection: advances, challenges and opportunities', Ecography , 40(2), pp. 281-295. doi: 10.1111/ecog.02445.

Guisan, A. and Thuiller, W. (2005) 'Predicting species distribution: Offering more than simple habitat models', Ecology Letters , 8(9), pp. 993-1009. doi: 10.1111/j.1461-0248.2005.00792.x.

Hayman, D. T. S. et al. (2010) 'Long-term survival of an urban fruit bat seropositive for ebola and lagos bat viruses', PLoS ONE , 5(8), p. e11978. doi: 10.1371/journal.pone.0011978.

Hernandez, P. A. et al. (2006) 'The effect of sample size and species characteristics on performance of different species distribution modeling methods', Ecography, 29(5), pp. 773-785. doi: DOI 10.1111/j.09067590.2006.04700.x.

Hortal, J. et al. (2008) 'Historical bias in biodiversity inventories affects the observed environmental niche of the species',Oikos , 117(6), pp. 847-858. doi: 10.1111/j.0030-1299.2008.16434.x.

Hutchinson, G. E. (1957) 'Concluding remarks', Cold Spring Harbor Symposia on Quantitative Biology , 22, pp. 415-427. doi: 10.1101/SQB.1957.022.01.039.

Jarnevich, C. S. et al. (2015) 'Caveats for correlative species distribution modeling', Ecological Informatics , 29(1), pp. 6-15. doi: 10.1016/j.ecoinf.2015.06.007.

Jennings, A. P. et al. (2013) 'Predicted distributions and conservation status of two threatened Southeast Asian small carnivores: The banded civet and Hose 's civet', Mammalia , 77(3), pp. 261-271. doi: 10.1515/mammalia-2012-0110.

Johnson, C. J. and Gillingham, M. P. (2008) 'Sensitivity of species-distribution models to error, bias, and model design: An application to resource selection functions for woodland caribou',Ecological Modelling , 213(2), pp. 143-155. doi: 10.1016/j.ecolmodel.2007.11.013.

Jones, K. E. et al. (2008) 'Global trends in emerging infectious diseases', Nature, 451, pp. 990-993. doi: 10.1038 /nature06536.

Kadmon, R., Farber, O. and Danin, A. (2003) 'A systematic analysis of factors affecting the performance of climatic envelope models',Ecological Applications , 13(3), pp. 853-867. doi: 10.1890/10510761(2003)013[0853:ASAOFA]2.0.CO;2.

Kadmon, R., Farber, O. and Danin, A. (2004) 'Effect of roadside bias on the accuracy of predictive maps produced by bioclimatic models',Ecological Applications , 14(2), pp. 401-413. doi: 10.1890/02-5364.

Knut, S.-N. (1997) Animal physiology. Adaptation and Environment . 5th ed. Cambridge University Press.

Lahoz-Monfort, J. J., Guillera-Arroita, G. and Wintle, B. A. (2014) 'Imperfect detection impacts the performance of species distribution models', Global Ecology and Biogeography , 23(4), pp. 504-515. doi: 10.1111/geb.12138.

Leroy, E. M. et al. (2004) 'Multiple Ebola Virus Transmission Events and Rapid Decline of Central African Wildlife', Science, 303(5656), pp. 387-390. doi: 10.1126/science.1092528.

Leroy, E. M. et al. (2005) 'Fruit bats as reservoirs of Ebola virus', Nature , 438(7068), pp. 575-576. doi: $10.1038 / 438575$ a.

Leroy, J. L. et al. (2007) 'Current priorities in health research funding and lack of impact on the number of child deaths per year',American Journal of Public Health , 97(2), pp. 219-223. doi: 10.2105/AJPH.2005.083287.

Lindsay, S. W. et al. (2010) 'Assessing the future threat from vivax malaria in the United Kingdom using two markedly different modelling approaches', Malaria Journal , 9(1), p. 70. doi: 10.1186/1475-2875-9-70. 
Lobo, J. M., Jimenez-valverde, A. and Real, R. (2008) 'AUC: A misleading measure of the performance of predictive distribution models', Global Ecology and Biogeography , 17(2), pp. 145-151. doi: 10.1111/j.14668238.2007.00358.x.

Maganga, G. D. et al. (2014) 'Ebola Virus Disease in the Democratic Republic of Congo', New England Journal of Medicine, 371(22), pp. 2083-2091. doi: 10.1056/NEJMoa1411099.

Martinez-Meyer, E. (2005) 'Climate Change and Biodiversity: Some Considerations in Forecasting Shifts in Species' Potential Distributions', Biodiversity Informatics , 2, pp. 42-55. doi: 10.17161/bi.v2i0.8.

Martinez-Meyer, E., Peterson, A. T. and Hargrove, W. W. (2004) 'Ecological niches as stable distributional constraints on mammal species, with implications for Pleistocene extinctions and climate change projections for biodiversity', Global Ecology and Biogeography , 13(4), pp. 305-314. doi: 10.1111/j.1466822X.2004.00107.x.

McInerny, G. J. and Etienne, R. S. (2013) "Niche" or "distribution" modelling? A response to Warren', Trends in Ecology and Evolution, 28(4), pp. 191-192. doi: 10.1016/j.tree.2013.01.007.

McPherson, J. and Jetz, W. (2007) 'Effects of species' ecology on the accuracy of distribution models', Ecography , 30(1), pp. 135-151. doi: 10.1111/j.2006.0906-7590.04823.x.

Newson, S. E. et al. (2009) 'Indicators of the impact of climate change on migratory species', Endangered Species Research , 7, pp. 101-113. doi: 10.3354/esr00162.

Nyakarahuka, L. et al. (2017) 'Ecological Niche Modeling for Filoviruses: A Risk Map for Ebola and Marburg Virus Disease Outbreaks in Uganda', PLOS Currents Outbreaks , 9. doi: 10.1371/currents.outbreaks.07992a87522e1f229c7cb023270a2af1.

Olival, K. J. and Hayman, D. T. S. (2014) 'Filoviruses in bats: Current knowledge and future directions', Viruses , 6(4), pp. 1759-1788. doi: 10.3390/v6041759.

Omoleke, S. A., Mohammed, I. and Saidu, Y. (2016) 'Ebola viral disease in West Africa: A threat to global health, economy and political stability', Journal of Public Health in Africa , 7(1), pp. 27-40. doi: 10.4081/jphia.2016.534.

Osborne, P. E. and Leitao, P. J. (2009) 'Effects of species and habitat positional errors on the performance and interpretation of species distribution models', Diversity and Distributions , 15(4), pp. 671-681. doi: 10.1111/j.1472-4642.2009.00572.x.

Osterholm, M. T., Moore, K. A. and Gostin, L. O. (2015) 'Public health in the age of ebola in west africa', JAMA Internal Medicine, 175(1), pp. 7-8. doi: 10.1001/jamainternmed.2014.6235.

Papeş, M. and Gaubert, P. (2007) 'Modelling ecological niches from low numbers of occurrences: Assessment of the conservation status of poorly known viverrids (Mammalia, Carnivora) across two continents',Diversity and Distributions , 13(6), pp. 890-902. doi: 10.1111/j.1472-4642.2007.00392.x.

Pautasso, M. et al. (2010) 'Plant health and global change - Some implications for landscape management', Biological Reviews . doi: 10.1111/j.1469-185X.2010.00123.x.

Pearce, J., Ferrier, S. and Scotts, D. (2001) 'An evaluation of the predictive performance of distributional models for flora and fauna in north-east New South Wales', Journal of Environmental Management ,62(2), pp. 171-184. doi: 10.1006/jema.2001.0425.

Perkins, S. E. et al. (2007) 'Evaluation of the AR4 climate models' simulated daily maximum temperature, minimum temperature, and precipitation over Australia using probability density functions', Journal of Climate, 20(17), pp. 4356-4376. doi: 10.1175/JCLI4253.1.

Peterson, A. T. (2003) 'Predicting the Geography of Species' Invasions via Ecological Niche Modeling', The Quarterly Review of Biology, 78(4), pp. 419-433. doi: 10.1086/378926. 
Peterson, A. T., Carroll, D. S., et al. (2004) 'Potential mammalian filovirus reservoirs', Emerging Infectious Diseases , 10(12), pp. 2073-2081. doi: 10.3201/eid1012.040346.

Peterson, A. T. (2006) 'Ecologic niche modeling and spatial patterns of disease transmission', Emerging Infectious Diseases , 12(12), p. Ecologic niche modeling and spatial patterns of di. doi: 10.3201/eid1212.060373.

Peterson, A. T. et al. (2007) 'Mammal Taxa Constituting Potential Coevolved Reservoirs of Filoviruses', Journal of Mammalogy, 88(6), pp. 1544-1554. doi: 10.1037/0022-3514.45.5.1096.

Peterson, A. T., Bauer, J. T. and Mills, J. N. (2004) 'Ecologic and Geographic Distribution of Filovirus Disease', Emerging Infectious Diseases , 10(1), pp. 40-47. doi: 10.3201/eid1001.030125.

Phillips, S. (2017) 'maxnet: Fitting "Maxent" Species Distribution Models with "glmnet", $R$ Package , p. version 0.1 .

Phillips, S. J. et al. (2009) 'Sample selection bias and presence-only distribution models: Implications for background and pseudo-absence data', Ecological Applications , 19(1), pp. 181-197. doi: 10.1890/07-2153.1.

Phillips, S. J. et al. (2017) 'Opening the black box: an open-source release of Maxent', Ecography, 40(7), pp. 887-893. doi: 10.1111/ecog.03049.

Phillips, S. J., Anderson, R. P. and Schapire, R. E. (2006) 'Maximum entropy modeling of species geographic distributions', Ecological Modelling , 190(3-4), pp. 231-259. doi: 10.1016/j.ecolmodel.2005.03.026.

Phillips, S. J. and Dudík, M. (2008) 'Modeling of species distributions with Maxent: New extensions and a comprehensive evaluation',Ecography , 31(2), pp. 161-175. doi: 10.1111/j.0906-7590.2008.5203.x.

Pigott, D. M. et al. (2014) 'Mapping the zoonotic niche of Ebola virus disease in Africa', eLife, 3, p. e04395. doi: $10.7554 /$ eLife.04395.

Pourrut, X. et al. (2009) 'Large serological survey showing cocirculation of Ebola and Marburg viruses in Gabonese bat populations, and a high seroprevalence of both viruses in Rousettus aegyptiacus', $B M C$ Infectious Diseases , 9(159). doi: 10.1186/1471-2334-9-159.

R Development Core Team (2018) 'R statistical software', R: A Language and Environment for Statistical Computing . Vienna, Austria: R Foundation for Statistical Computing.

Rainho, A., Augusto, A. M. and Palmeirim, J. M. (2010) 'Influence of vegetation clutter on the capacity of ground foraging bats to capture prey', Journal of Applied Ecology , 47(4), pp. 850-858. doi: 10.1111/j.13652664.2010.01820.x.

Reddy, S. and Dávalos, L. M. (2003) 'Geographical sampling bias and its implications for conservation priorities in Africa', Journal of Biogeography , 30(11), pp. 1719-1727. doi: 10.1046/j.1365-2699.2003.00946.x.

Report of a WHO/International Study Team (1978) 'Ebola haemorrhagic fever in Sudan, 1976', Bulletin of the World Health Organization, 56(2), pp. 247-270. doi: 1978;56(2):247-270.

Robinson, R. A. et al. (2009) 'Travelling through a warming world: Climate change and migratory species', Endangered Species Research, 7(2), pp. 87-99. doi: 10.3354/esr00095.

Royle, J. A., Nichols, J. D. and Kéry, M. (2005) 'Modelling occurrence and abundance of species when detection is imperfect', Oikos , 110(2), pp. 353-359. doi: 10.1111/j.0030-1299.2005.13534.x.

Russo, D., Cistrone, L. and Jones, G. (2012) 'Sensory Ecology of Water Detection by Bats: A Field Experiment', PLoS ONE , 7(10), p. e48144. doi: 10.1371/journal.pone.0048144.

Segurado, P., Araújo, M. B. and Kunin, W. E. (2006) 'Consequences of spatial autocorrelation for niche-based models', Journal of Applied Ecology , 43(3), pp. 433-444. doi: 10.1111/j.1365-2664.2006.01162.x.

Soberón, J. (2007) 'Grinnellian and Eltonian niches and geographic distributions of species', Ecology Letters , 10(12), pp. 1115-1123. doi: 10.1111/j.1461-0248.2007.01107.x. 
Stephens, P. A. et al. (2015) 'Management by proxy? The use of indices in applied ecology', Journal of Applied Ecology, 52(1), pp. 1-6. doi: 10.1111/1365-2664.12383.

Stigall, A. L. (2012) 'Using ecological niche modelling to evaluate niche stability in deep time', Journal of Biogeography , 39(4), pp. 772-781. doi: 10.1111/j.1365-2699.2011.02651.x.

Thomas, D. W. and Cloutier, D. (1992) 'Evaporative Water Loss by Hibernating Little Brown Bats, Myotis lucifugus', Physiological Zoology, 65, pp. 443-456. doi: 10.1086/physzool.65.2.30158262.

Thorn, J. S. et al. (2009) 'Ecological niche modelling as a technique for assessing threats and setting conservation priorities for Asian slow lorises (Primates: Nycticebus)', Diversity and Distributions , 15(2), pp. 289-298. doi: 10.1111/j.1472-4642.2008.00535.x.

Tsoar, A. et al. (2007) 'A comparative evaluation of presence-only methods for modelling species distribution',Diversity and Distributions , 13(4), pp. 397-405. doi: 10.1111/j.1472-4642.2007.00346.x.

Warren, C. C. et al. (2013) 'Detection heterogeneity and abundance estimation in populations of Goldencheeked Warblers', The Auk, 130(4), pp. 677-688. doi: 10.1525/auk.2013.13022.

Warren, D. L. and Seifert, S. N. (2011) 'Ecological niche modeling in Maxent : the importance of model complexity and the performance of model selection criteria C ommunications', Ecological Applications , 21(2), pp. 335-342. doi: 10.1890/10-1171.1.

Warton, D. I. and Shepherd, L. C. (2010) 'Poisson point process models solve the "pseudo-absence problem" for presence-only data in ecology',Annals of Applied Statistics , 4(3), pp. 1383-1402. doi: 10.1214/10AOAS331.

Wolfe, N. D. et al. (2005) 'Bushmeat hunting, deforestation, and prediction of zoonotic disease emergence', Emerging Infectious Diseases , 11(12), pp. 1822-1827. doi: 10.3201/eid1112.040789.

Wolfe, N. D., Dunavan, C. P. and Diamond, J. (2007) 'Origins of major human infectious diseases', Nature , 447(7142), pp. 279-283. doi: 10.1038/nature05775.

Yackulic, C. B. et al. (2013) 'Presence-only modelling using MAXENT: When can we trust the inferences?', Methods in Ecology and Evolution , 4(3), pp. 236-243. doi: 10.1111/2041-210x.12004.

Yoccoz, N. G., Nichols, J. D. and Boulinier, T. (2001) 'Monitoring of biological diversity in space and time', Trends in Ecology 83 Evolution, 16(8), pp. 446-453. doi: http://dx.doi.org/10.1016/S0169-5347(01)02205-4.

\section{FIGURE LEGENDS}

Figure 1 Occurrence locations of Hypsignathus monstrosus sightings in red (123 observations in Africa of which 9 in DR Congo), Myonycteris torquata sightings in blue (79 observations in Africa of which 7 in DR Congo) and Epomops franqueti sightings in green (201 observations in Africa of which 10 in DR Congo)

Figure 2 Receiver Operating Characteristic (ROC) curve and Area Under the Curve (AUC) value under the current period (100 runs) for Epomops franqueti (A), Hypsignathus monstrosus (B) andMyonycteris torquata (C).

Figure 3 Jackknife test for variable importance of Hypsignathus monstrosus (A), Myonycteris torquata (C) and Epomops franqueti (B) . Mean Diurnal Range (bio2), Min Temperature of Coldest Month (bio6), Annual Temperature Range (bio7), Temperature of Wettest Quarter (bio8), Mean Temperature of Driest Quarter (bio9), Mean Mean Temperature of Warmest Quarter bio10), Precipitation Seasonality (bio15), Precipitation of Wettest Quarter (bio16), Precipitation of Driest Quarter (bio17), Precipitation of Warmest Quarter (bio18), Precipitation of Coldest Quarter (bio19).

Figure 4 Response curves of the variables contributing most to the prediction by the MaxEnt models for Epomops franqueti, Hypsignathus monstrosus and Myonycteris torquata. Red indicates the mean response 
averaged over the 100 replicate MaxEnt runs, while blue indicates one standard deviation. For Epomops franqueti, bio7 (Annual Temperature Range) in Figure 4A had the largest percent contribution and the largest permutation importance, followed by bio17 (Precipitation of Driest Quarter) in Figure 4B. For Hypsignathus monstrosus, bio7 (Figure 4C) had the largest percent contribution; bio17 (Figure 4D) and bio19 (Precipitation of Coldest Quarter) in Figure 4E had the largest permutation importance. For Myonycteris torquata, bio17 (Figure 4F) and bio19 (Figure 4G) had the largest permutation importance.

Figure 5 Predicted current distribution of bats in DR Congo. The letters A, B, C, D in the maps represent the predicted distribution ofEpomops franqueti, Hypsignathus monstrosus, Myonycteris torquataand mean relative probability of presence respectively. Dark green indicates not suitable area (0.00 - 0.05); Light green indicates slightly suitable area $(0.05-0.25)$; Yellow indicates moderately suitable area $(0.25-0.50)$; Orange indicates suitable area (0.50 - 0.75); Red indicates highly suitable area $(0.75-1.00)$.

Figure 6 Predicted distribution of bats in DR Congo in 2050 under RCP 4.5 (top) and RCP 8.5 (bottom). The letters A, B, C, D in the maps represent the predicted distribution of Epomops franqueti, Hypsignathus monstrosus, Myonycteris torquata and mean relative probability of presence respectively. Dark green indicates not suitable area $(0.00-0.05)$; Light green indicates slightly suitable area (0.05 - 0.25); Yellow indicates moderately suitable area $(0.25-0.50)$; Orange indicates suitable area $(0.50-0.75)$; Red indicates highly suitable area $(0.75-1.00)$.

Figure 7 Predicted distribution of bats in DR Congo in 2070 under RCP 4.5 (top) and RCP 8.5 (bottom). The letters A, B, C, D in the maps represent the predicted distribution of Epomops franqueti, Hypsignathus monstrosus, Myonycteris torquata and mean relative probability of presence respectively. Dark green indicates not suitable area $(0.00-0.05)$; Light green indicates slightly suitable area (0.05 - 0.25); Yellow indicates moderately suitable area $(0.25-0.50)$; Orange indicates suitable area $(0.50-0.75)$; Red indicates highly suitable area $(0.75-1.00)$. 


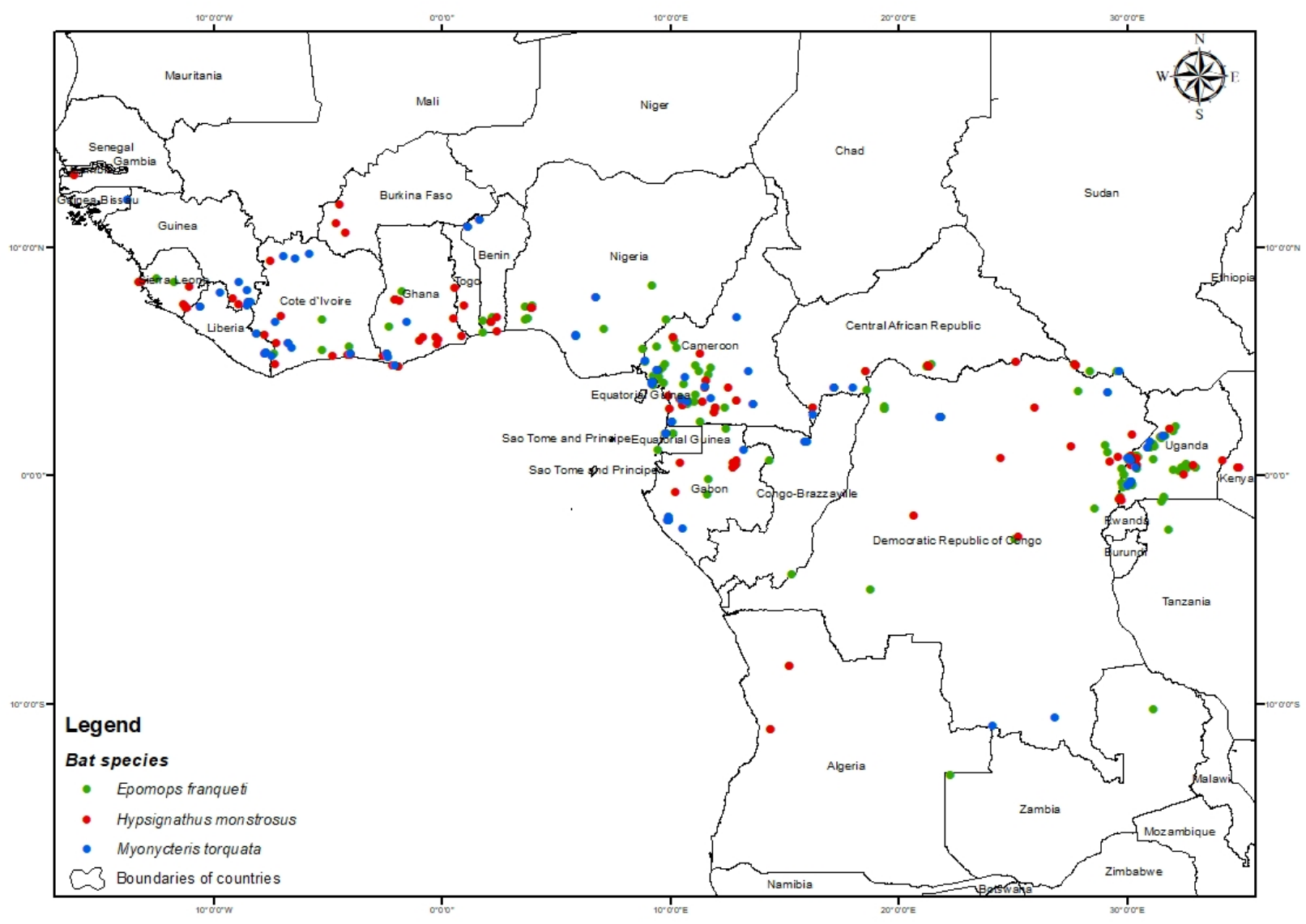

FIGURE 1 

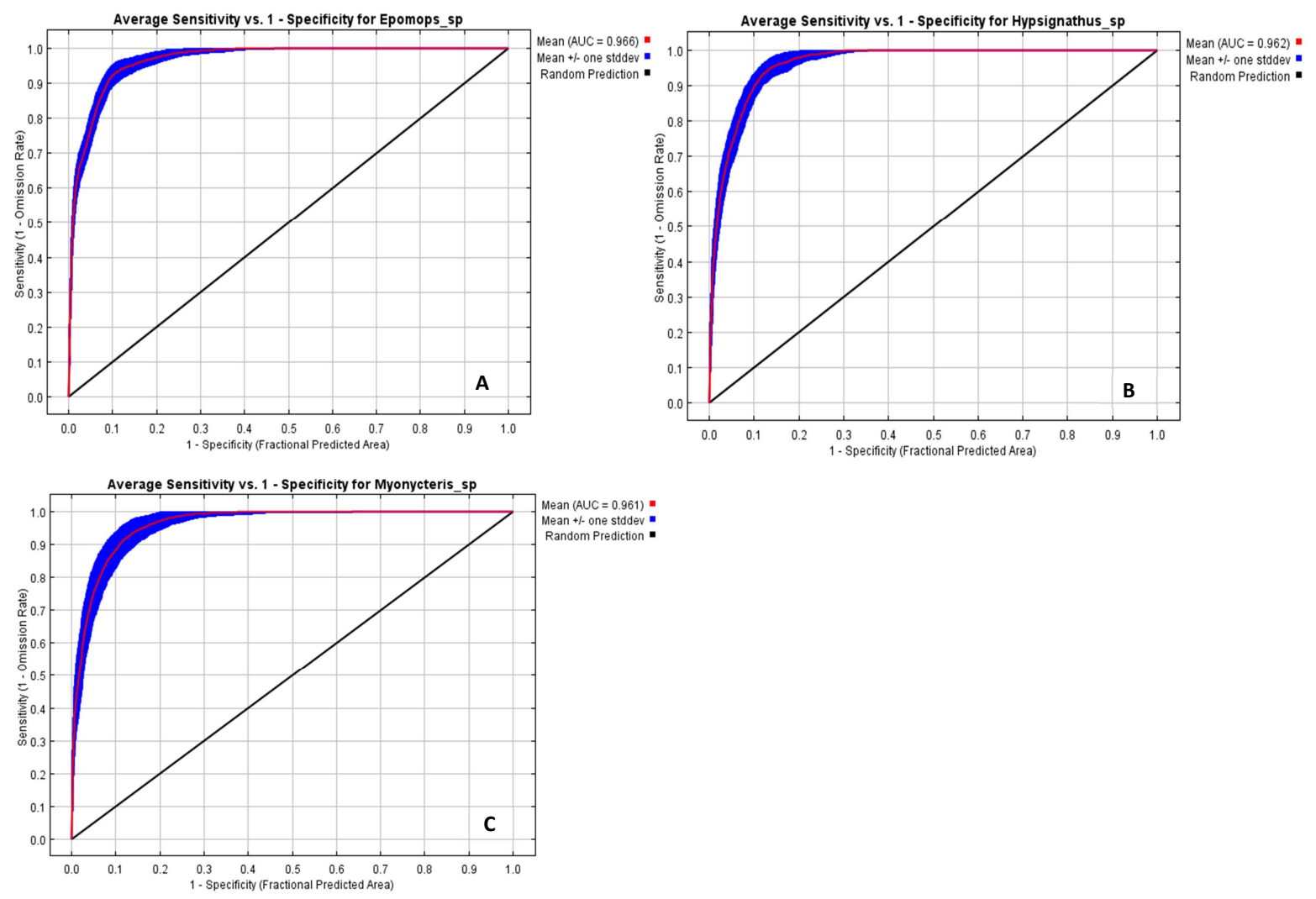

FIGURE 2 

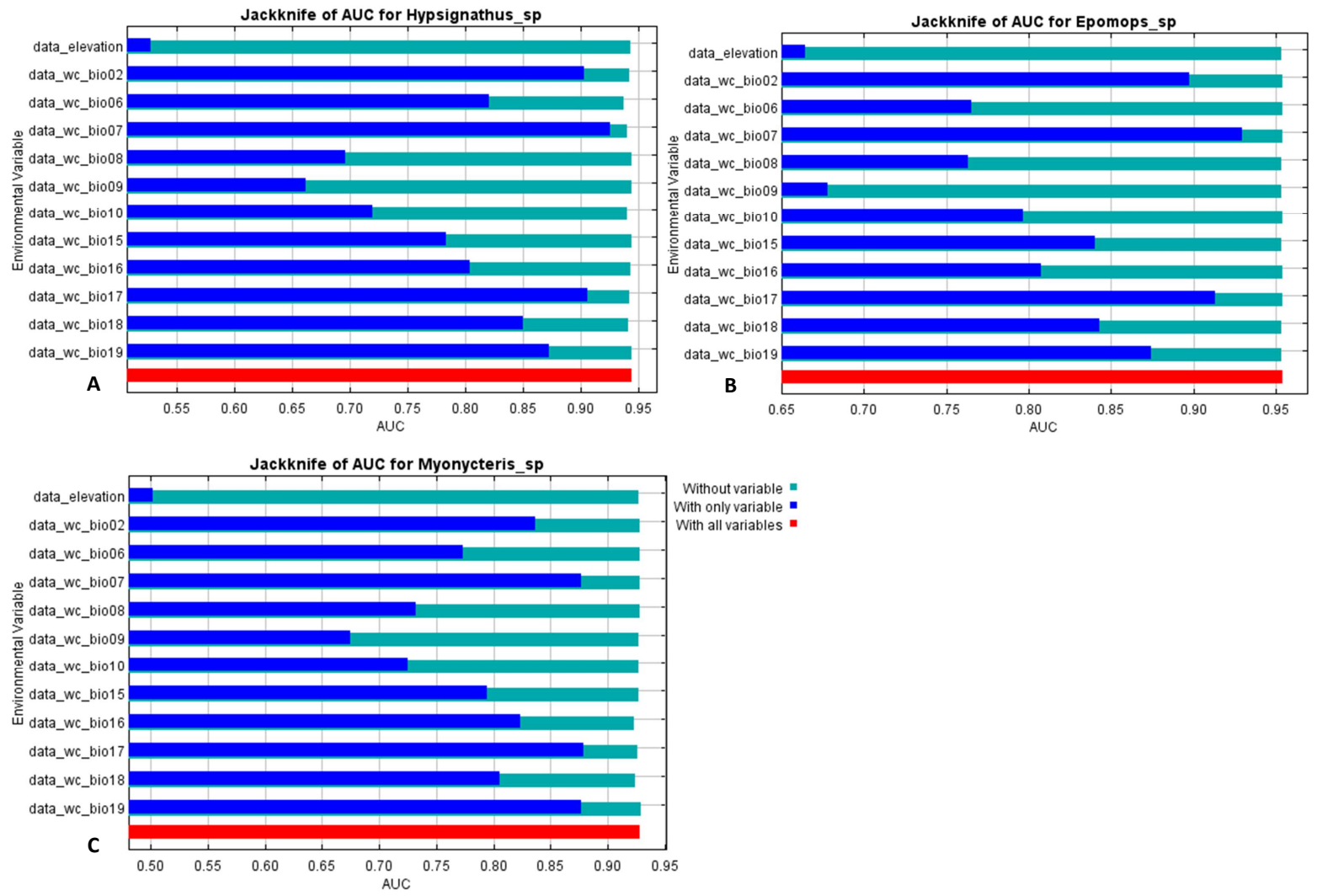

Without variable = With only variable = With all variables =

FIGURE 3 

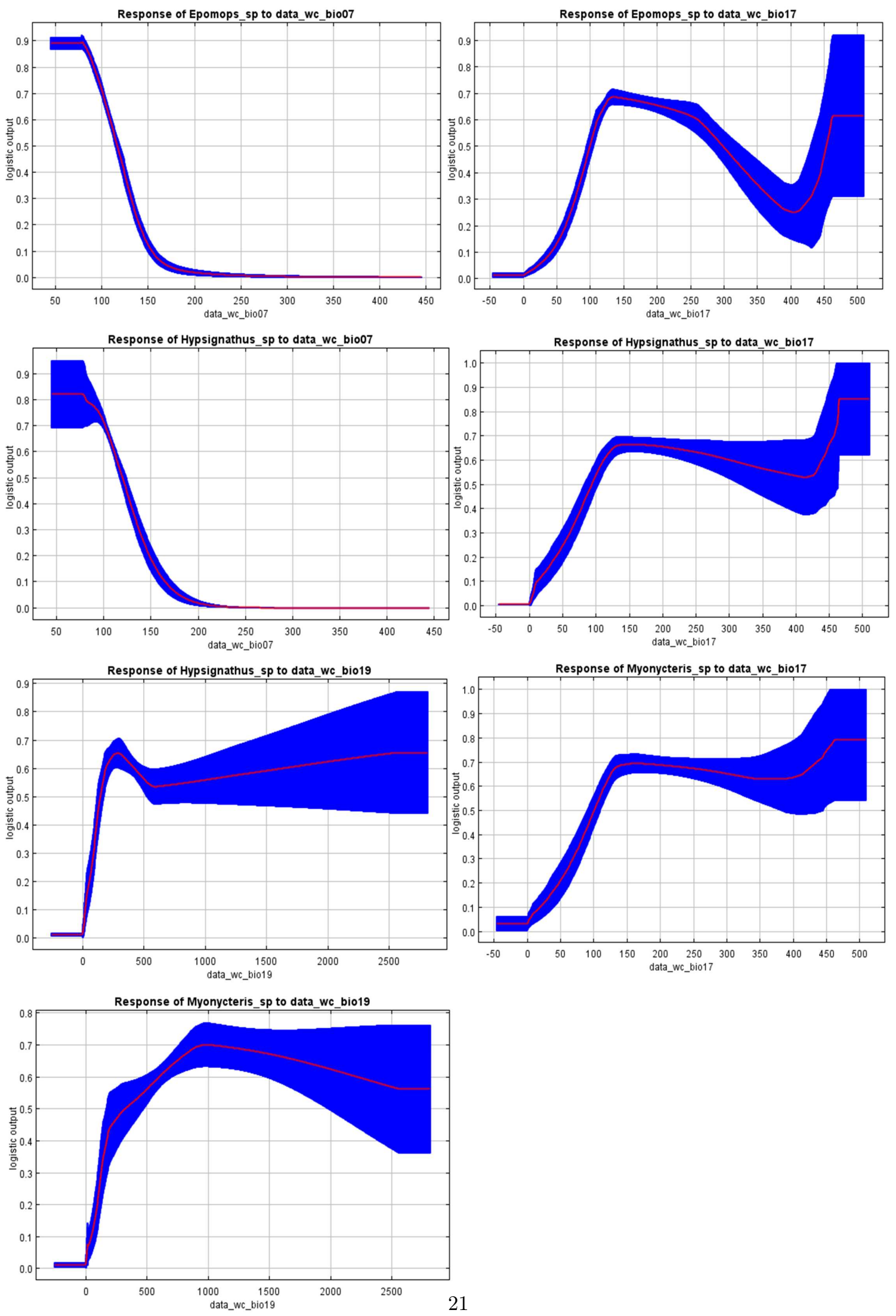
FIGURE 4 

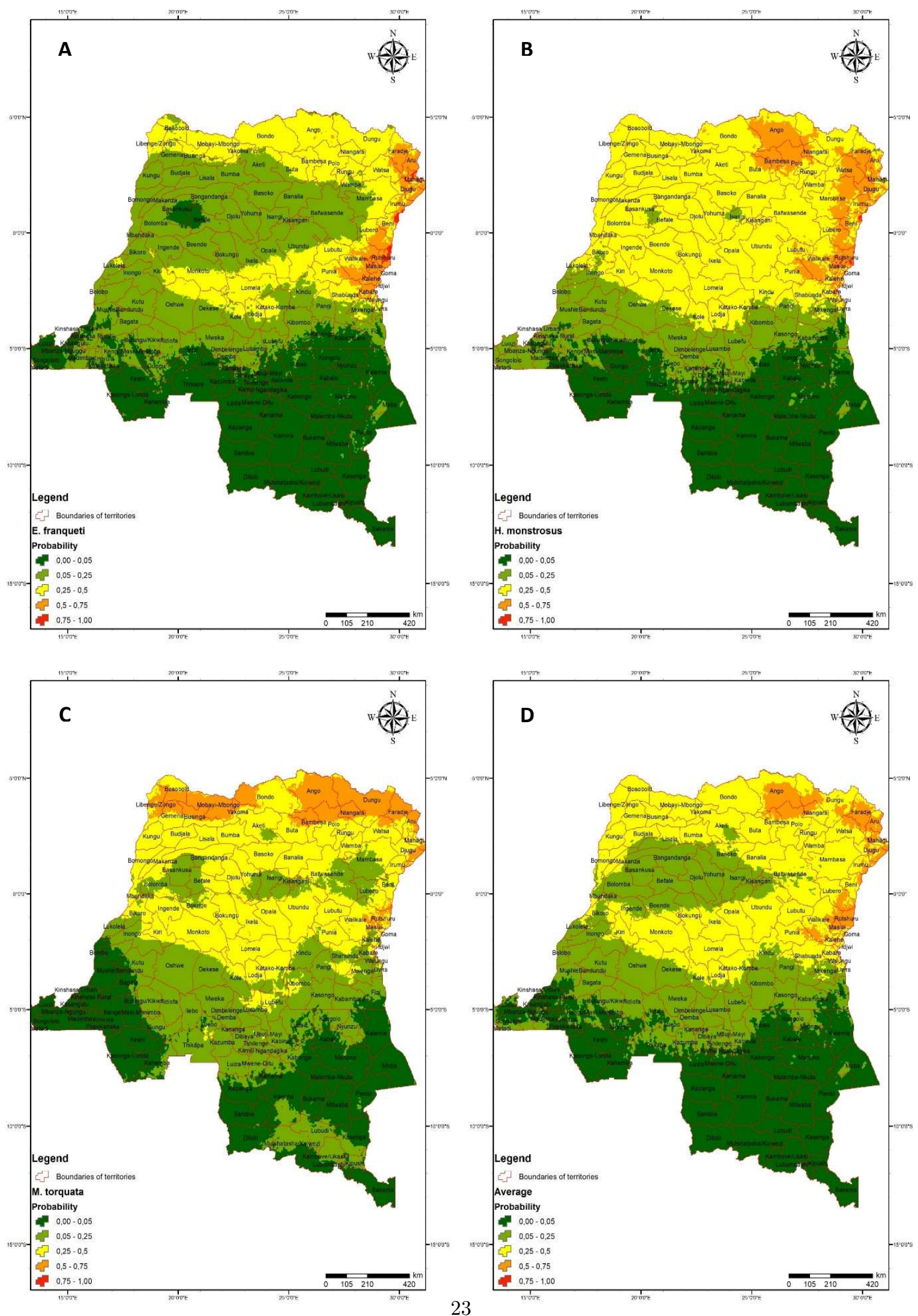
FIGURE 5
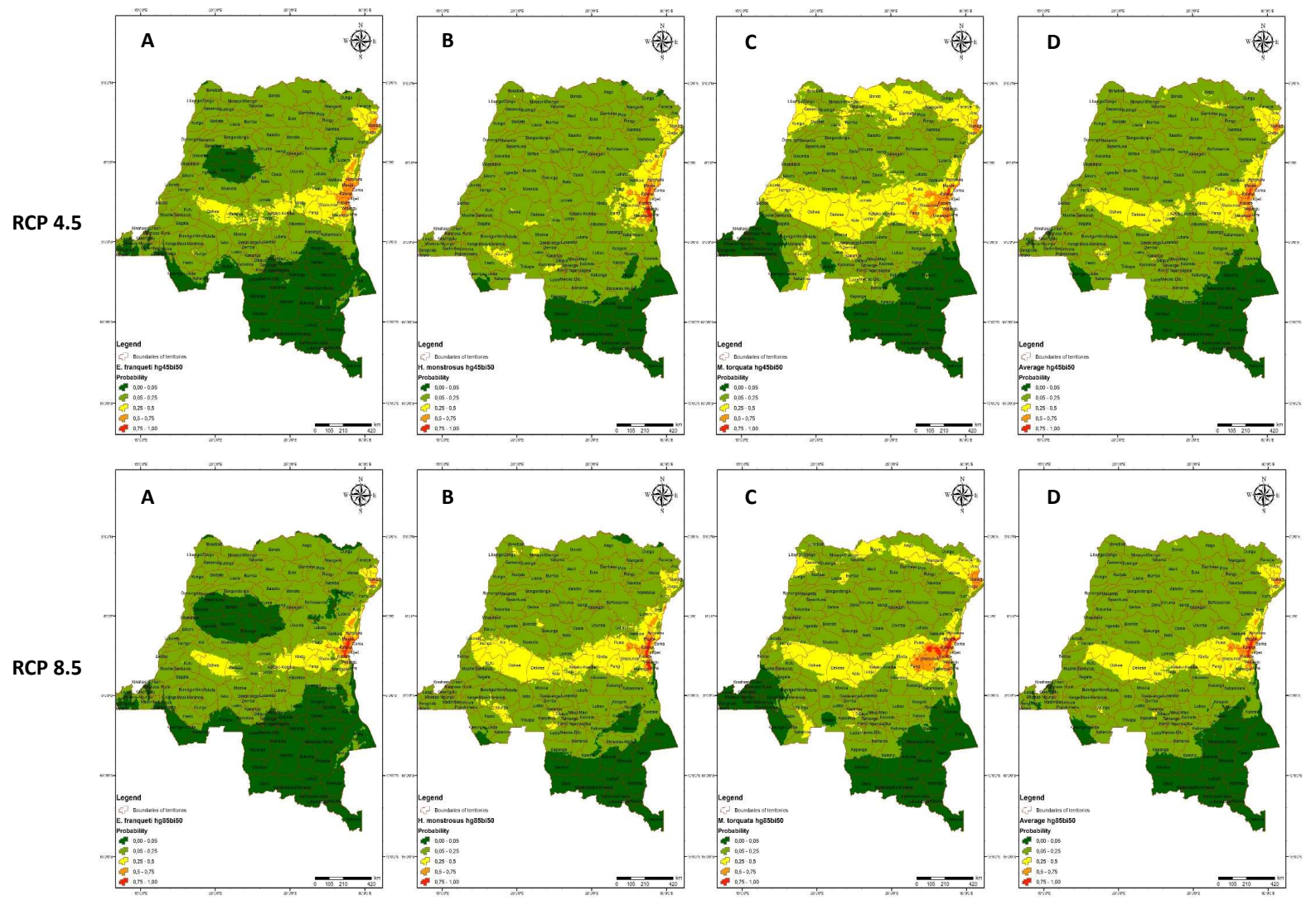

FIGURE 6 

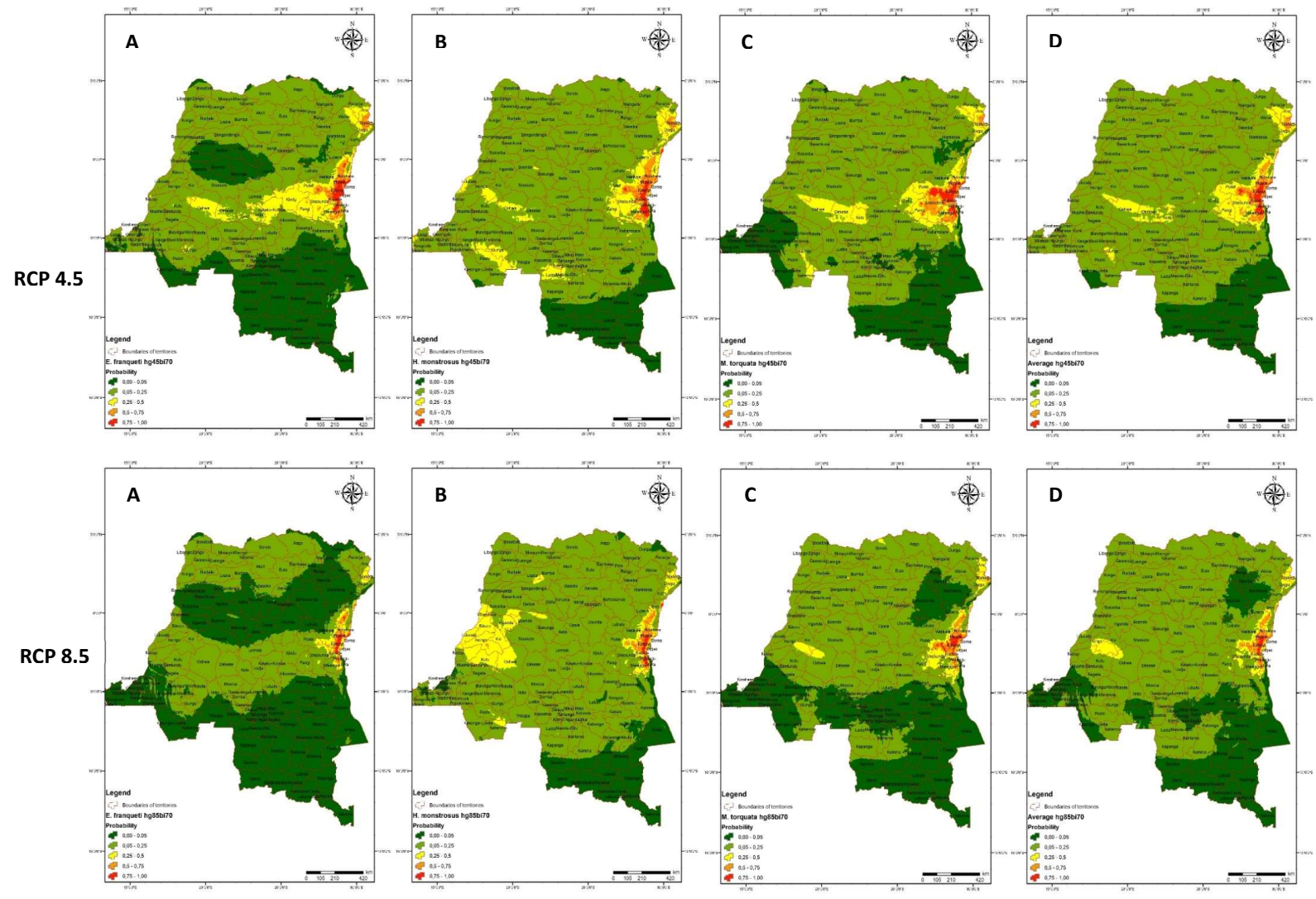

FIGURE 7 